\title{
Research on Evaluation and Selection of the Third Party Logistics Supplier
}

\author{
Jinhua Li \\ Yantai Nanshan University \\ Yantai, China
}

\author{
Min Liu \\ Yantai Nanshan University \\ Yantai, China
}

\author{
Xiaojie Chai \\ Yantai Nanshan University \\ Yantai, China
}

\begin{abstract}
Through analyzing the characteristics of fresh agricultural products, this paper set up the third party logistics provider selection index system, and construct the selection model based on fuzzy comprehensive evaluation. At the end of the paper introduces the example analysis, to demonstrate the effectiveness and practicability of the model.
\end{abstract}

Keywords-fuzzy comprehensive evaluation method; fresh agricultural products; the third party logistics provider

\section{INTRODUCTION}

Data shows that the fresh agricultural products in picking, transportation, storage, distribution and other logistics link loss rate at about $25 \% \sim 30 \%$, the value of the loss of nearly 100 billion RMB. And the quality and safety of agricultural products controversial [1]. In contrast, in the United States and other developed countries, fresh agricultural products quality is safe and reliable, which has low loss rate, loss rate between $1 \%$ $\sim 2 \%$, only because of using the entire cold chain management [2]. So how to choose the third party logistics provider, the smooth and efficient production of fresh agricultural products from the field transmitted to consumers, become very worthy of attention and research topic. This paper uses the method of fuzzy comprehensive evaluation, selection of third party logistics suppliers of fresh agricultural products, has important theoretical and practical significance.

\section{ANALYSIS OF THE CHARACTERISTICS OF FRESH AGRICULTURAL PRODUCTS}

\section{A. The Production Characteristics of Fresh Agricultural Products}

Production characteristics of fresh agricultural products is the production of seasonal and dispersion. Seasonal agricultural products mainly refers to the harvest season is basically fixed. Dispersion refers to the vast majority of agricultural products and agricultural products are operated by individual farmers scattered, individual farmers and dispersion are "small production" mode, the production increase the fresh agricultural products logistics difficulty.

\section{B. The Circulation Characteristics of Fresh Agricultural Products}

Circulation characteristic mainly displays in timeliness, perishable etc. The timeliness requirements of fresh agricultural products as far as possible to shorten the radius of the logistics, improve the logistics technology including transportation technology, handling technology, distribution technology and so on, to achieve rapid logistics quality. Perishable characteristics of fresh agricultural products are required to change the traditional constant temperature logistics. It puts forward higher technical requirements on logistics providers, related factors should be considered when choosing.

\section{THE THIRD PARTY LOGISTICS PROVIDER EVALUATION} INDEX SYSTEM BASED ON FRESH AGRICULTURAL PRODUCTS

The choice of logistics service suppliers is a very complicated process. Because logistics providers selection goal often is not the only target, these many goals together constitute the index system. Taking into account the fresh agricultural products are perishable, easy loss characteristics, usually need to cold treatment, this paper established third party logistics providers evaluation system, combined with the requirements of the third party logistics providers in the fresh agricultural products supply chain, as shown in "Fig. 1". 


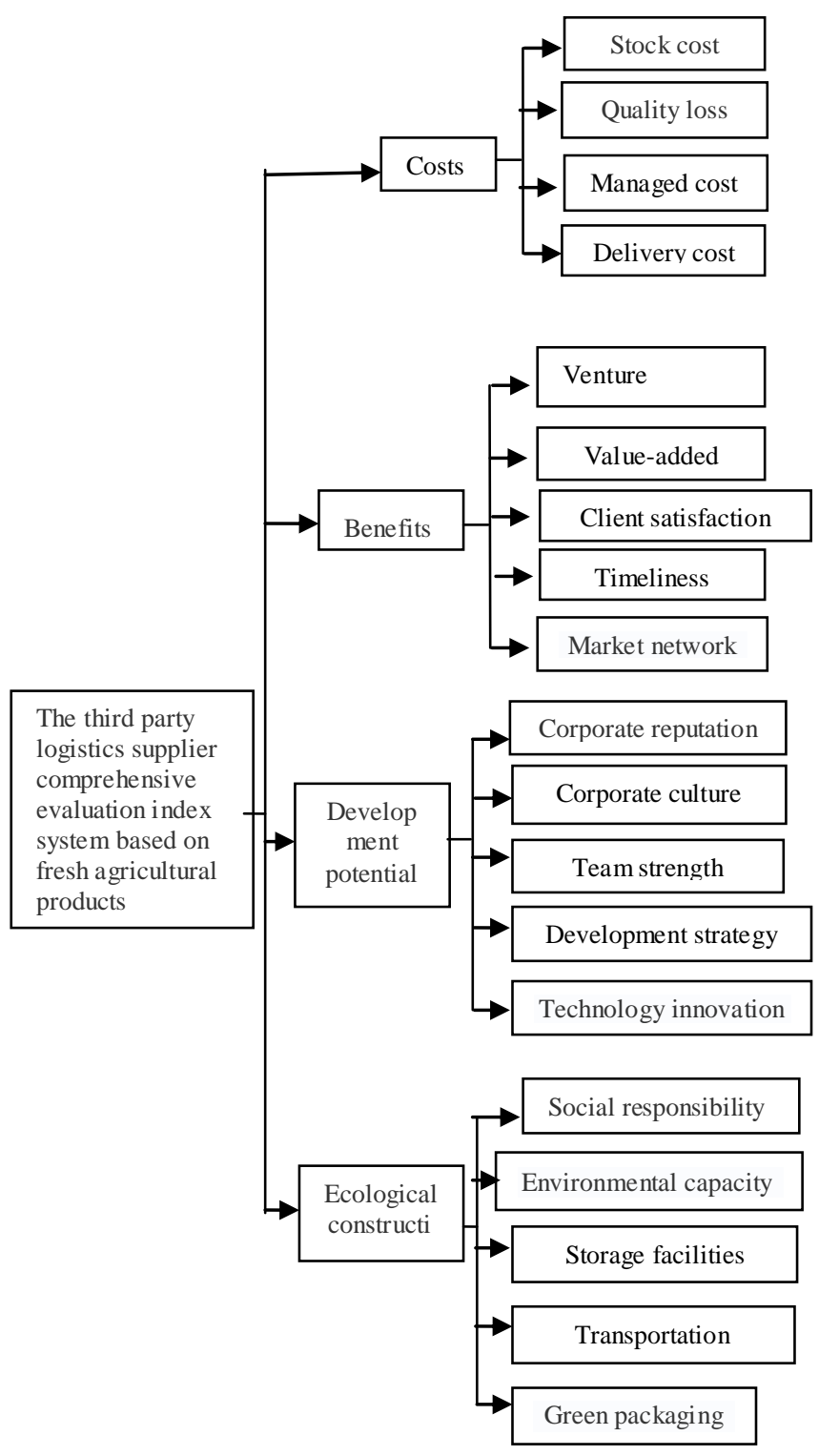

Fig. 1. The third party logistics supplier selection evaluation index system based on fresh agricultural products

\section{The CONSTRUCtion OF MODEL SELECTION}

Fuzzy comprehensive evaluation method is a kind of comprehensive evaluation method, refers to the factors quantitatively, border is not clear, is not easy to be quantitative, are based on fuzzy mathematics, It has the advantages of concise analytic hierarchy system, at the same time, the qualitative description and quantitative analysis closely together, and solves the problem to quantify the qualitative evaluation index is difficult, can be said to be an evaluation method of more reasonable and scientific[3]. The specific evaluation process is as follows.

\section{A. The Establishment of Fuzzy Sets}

The evaluation factors set $\mathrm{U}$, with $\mathrm{m}$ of evaluation factors, there are $U=\left(u_{1}, u_{2}, \Lambda, u_{m}\right)$, where $u_{i}$ is the $\mathrm{i}$ evaluation factors.

Reviews the set $\mathrm{V}$, with $\mathrm{n}$ ratings, is composed of the following set of grade evaluation: $V=\left(v_{1}, v_{2}, v_{3}, \Lambda, v_{n}\right)$.

Evaluation of matrix $\mathrm{R}$ represents the fuzzy relationship between the evaluation factor set $\mathrm{U}$ and comments set $\mathrm{V}$ :

$$
R=\left(\begin{array}{ccc}
r_{11} & \Lambda & r_{1 m} \\
\mathrm{M} & \mathrm{O} & \mathrm{M} \\
r_{n 1} & \Lambda & r_{n m}
\end{array}\right)
$$

Where, represents the corresponding to the evaluation factors of, that is the object of the $\mathrm{j}$ comments. Matrix of the line $i$, as the single factor evaluation of the $i$ evaluation elements, it is a comment on a sub domain on the set.

\section{B. The AHP to Determine the Weight}

In the fuzzy comprehensive evaluation, the need to determine the weight vector of evaluation factors. For the multi factor evaluation, the influence degree of various factors to consider in the overall evaluation, the extent of influence factors of formation in a fuzzy subset of A, on the factor set $U$. where is for A membership. This paper uses the analytic hierarchy process (AHP) to determine the index between the relative importance of the order, so as to determine the weight coefficient.

- Establish the hierarchical structure and determine the objectives and evaluation factors. The problem of factors are grouped, each a group as a hierarchy.

- Construction of the judgment matrix. Two comparison is adopted to establish the method of paired comparison matrix, with 1-9 and its inverse as a general scale to assess the status of the relative importance of each element, as shown in "Table I".

TABLE I. ELEMENTS OF RELATIVE IMPORTANCE SCALE

\begin{tabular}{ll}
\hline \multicolumn{1}{c}{ Scale } & \multicolumn{1}{c}{ Signification } \\
\hline 1 & $\begin{array}{l}\text { Compared to two factors are equally important } \\
\text { Compared to two factors, the former is slightly more } \\
\text { important than the latter } \\
\text { Compared to two factors, the former is more important } \\
\text { than the latter obviously } \\
\text { Compared to two factors, the former is more important } \\
\text { than the latter strongly } \\
\text { Compared to two factors, the former than the latter is } \\
\text { extremely important } \\
\text { The middle of the adjacent judgment Above-mentioned }\end{array}$ \\
\hline
\end{tabular}

- The weight calculation. Approximate eigenvector corresponding to the largest judgment matrix and its characteristic roots by square root method. To determine the calculation of product of each row of the matrix: 
The calculation of $n$-th root of:

The normalized vector:

And then is the requested feature vector.

- The consistency test. The biggest characteristic root is as follows:

For the test of consistency of judgment matrix, there is need to calculate consistency index and the average random consistency index RI. When the random consistency ratio, that is, weights allocation is reasonable. Otherwise, the pair wise comparison matrix is used to adjust the value, to distribution coefficient values.

\section{Fuzzy Comprehensive Evaluation}

Fuzzy transform evaluation:

$$
B=\left(b_{1}, b_{2}, \Lambda, b_{n}\right)=\left(a_{1}, a_{2}, \Lambda, a_{n}\right)\left(\begin{array}{ccc}
r_{11} & \Lambda & r_{1 m} \\
\mathrm{M} & \mathrm{O} & \mathrm{M} \\
r_{n 1} & \Lambda & r_{n m}
\end{array}\right)
$$

Where, $\mathrm{B}$ as the evaluation set is equivalent to $\mathrm{V}$ of the fuzzy subset; ${ }^{b_{j}}$ is equivalent membership degree of fuzzy subset B. If making a decision, according to the maximum membership degree principle, the biggest $b_{j}$ corresponding grade $\mathrm{V}$ as the result of comprehensive evaluation.

\section{THE EMPIRICAL STUDY}

A fresh agricultural products enterprise is looking for logistics providers to bear the corresponding logistics business. The existing four alternative suppliers, respectively is a, b, c, d, to establish the criterion of the evaluation index system based on the cost, benefit, development potential and ecological construction. Concrete analysis is as follows:

Firstly, the establishment of fuzzy sets. Comments set $^{V}=$ (excellent, good, general, poor), regulations:

$$
V_{1}=4, V_{2}=3, V_{3}=2, V_{1}=1 \text {. }
$$

Secondly, determine the weight. After the discussion leaders and experts group, combined with the actual situation of the enterprise obtains the relative weight of four criteria, represented by the judgment matrix, as shown in "TableII".

TABLE II. JUDGMENT MATRIX OF THE GENERAL OBJECTIVE CRITERIA

\begin{tabular}{lllll}
\hline \multicolumn{1}{c}{ Index } & Costs & Benefits & $\begin{array}{c}\text { Development } \\
\text { Potential }\end{array}$ & $\begin{array}{c}\text { Ecological } \\
\text { Construction }\end{array}$ \\
\hline Costs & 1 & 3 & 5 & 5 \\
Benefits & $1 / 3$ & 1 & 2 & 3 \\
$\begin{array}{l}\text { Development } \\
\text { potential }\end{array}$ & $1 / 5$ & $1 / 2$ & 1 & 1 \\
$\begin{array}{l}\text { Ecological } \\
\text { construction }\end{array}$ & $1 / 5$ & $1 / 3$ & 1 & 1 \\
\hline
\end{tabular}

According to the formula (5),
$\lambda_{\max }=4.034, C R=0.0126<0.1$, the judgment matrix has relatively satisfactory consistency.

$$
W=[0.566,0.229,0.108,0097]^{T}
$$

Similarly, A that the weight of each secondary index can be worked out:

$$
\begin{aligned}
& A_{1}=(0.338,0.358,0.159,0.145) \\
& A_{2}=(0.381,0.368,0.123,0.089,0.039) \\
& A_{3}=(0.340,0.063,0.178,0.285,0.134) \\
& A_{4}=(0.273,0.235,0.197,0.165,0.130)
\end{aligned}
$$

\begin{tabular}{|c|c|c|c|c|c|}
\hline Suppliers & Index & Excellent & Good & General & Poor \\
\hline \multirow{4}{*}{$\mathrm{a}$} & Stock cost & 0.8 & 0.1 & 0.05 & 0.05 \\
\hline & $\begin{array}{l}\text { Managed } \\
\text { cost }\end{array}$ & 0.5 & 0.3 & 0.1 & 0.1 \\
\hline & Quality loss & 0.3 & 0.2 & 0.4 & 0.1 \\
\hline & $\begin{array}{l}\text { Delivery } \\
\text { cost }\end{array}$ & 0.2 & 0.5 & 0.3 & 0.0 \\
\hline \multirow{4}{*}{ b } & Stock cost & 0.75 & 0.05 & 0.2 & 0.0 \\
\hline & $\begin{array}{l}\text { Managed } \\
\text { cost }\end{array}$ & 0.8 & 0.2 & 0.0 & 0.0 \\
\hline & Quality loss & 0.6 & 0.2 & 0.1 & 0.1 \\
\hline & $\begin{array}{l}\text { Delivery } \\
\text { cost }\end{array}$ & 0.5 & 0.5 & 0.0 & 0.0 \\
\hline \multirow{4}{*}{$\mathrm{c}$} & Stock cost & 0.3 & 0.3 & 0.2 & 0.2 \\
\hline & $\begin{array}{l}\text { Managed } \\
\text { cost }\end{array}$ & 0.4 & 0.3 & 0.1 & 0.2 \\
\hline & Quality loss & 0.9 & 0.1 & 0.0 & 0.0 \\
\hline & $\begin{array}{l}\text { Delivery } \\
\text { cost }\end{array}$ & 0.9 & 0.1 & 0.0 & 0.0 \\
\hline \multirow{4}{*}{ d } & Stock cost & 0.6 & 0.3 & 0.1 & 0.0 \\
\hline & $\begin{array}{l}\text { Managed } \\
\text { cost }\end{array}$ & 0.5 & 0.3 & 0.1 & 0.1 \\
\hline & Quality loss & 0.4 & 0.5 & 0.0 & 0.1 \\
\hline & $\begin{array}{l}\text { Delivery } \\
\text { cost }\end{array}$ & 0.6 & 0.2 & 0.2 & 0.0 \\
\hline
\end{tabular}

Thirdly, the fuzzy comprehensive evaluation. After experts the objective evaluation of each supplier, and the "cost" factors in the primary index score evaluation results as shown in "Table III".

TABLE III. EVALUATION RESULTS OF COSTS

Thus, it can be concluded that the evaluation matrix $\mathrm{R}$ of cost index in the first level index system of a supplier. According to the weight of each index, it is concluded that supplier a, b, c, d costs in the first layer of the index system of evaluation indicators secondary comprehensive evaluation:

$$
\begin{aligned}
& B_{1 \mathrm{a}}=(0.526,0.245,0.160,0.069) \\
& B_{1 \mathrm{~b}}=(0.708,0.193,0.083,0.016) \\
& B_{1 \mathrm{c}}=(0.379,0.280,0.161,0.180) \\
& B_{1 d}=(0.532,0.317,0.099,0.052)
\end{aligned}
$$

According to the primary index under "benefit" in the secondary indicators of their weight, draw a supplier a, b, c, d secondary comprehensive evaluation:

$$
\begin{aligned}
& B_{2 a}=(0.567,0.229,0.132,0.072) \\
& B_{2 b}=(0.734,0.166,0.088,0.012)
\end{aligned}
$$




$$
\begin{aligned}
& B_{2 c}=(0.487,0.250,0.113,0.150) \\
& B_{2 d}=(0.531,0.323,0.097,0.049)
\end{aligned}
$$

Similarly, it is concluded the secondary comprehensive evaluation of a, b, c, d, which belongs to the "development potential":

$$
\begin{aligned}
& B_{3 a}=(0.494,0.271,0.180,0.055) \\
& B_{3 b}=(0.675,0.221,0.086,0.018) \\
& B_{3 c}=(0.664,0.181,0.074,0.081) \\
& B_{3 d}=(0.531,0.334,0.111,0.024)
\end{aligned}
$$

In the same way, it is concluded the secondary comprehensive evaluation of $\mathrm{a}, \mathrm{b}, \mathrm{c}, \mathrm{d}$, which belongs to the "Ecological construction":

\begin{tabular}{|c|c|c|c|c|c|}
\hline Suppliers & Index & Excellent & Good & General & Poor \\
\hline \multirow{4}{*}{$\mathrm{a}$} & Costs & 0.526 & 0.245 & 0.160 & 0.069 \\
\hline & Benefits & 0.567 & 0.229 & 0.132 & 0.072 \\
\hline & $\begin{array}{l}\text { Development } \\
\text { potential }\end{array}$ & 0.494 & 0.271 & 0.180 & 0.055 \\
\hline & $\begin{array}{l}\text { Ecological } \\
\text { construction }\end{array}$ & 0.506 & 0.259 & 0.165 & 0.070 \\
\hline \multirow{4}{*}{ b } & Costs & 0.708 & 0.193 & 0.083 & 0.016 \\
\hline & Benefits & 0.734 & 0.166 & 0.088 & 0.012 \\
\hline & $\begin{array}{l}\text { Development } \\
\text { potential }\end{array}$ & 0.675 & 0.221 & 0.086 & 0.018 \\
\hline & $\begin{array}{l}\text { Ecological } \\
\text { construction }\end{array}$ & 0.710 & 0.196 & 0.074 & 0.020 \\
\hline \multirow{4}{*}{$\mathrm{c}$} & Costs & 0.379 & 0.280 & 0.161 & 0.180 \\
\hline & Benefits & 0.487 & 0.250 & 0.113 & 0.150 \\
\hline & $\begin{array}{l}\text { Development } \\
\text { potential }\end{array}$ & 0.664 & 0.181 & 0.074 & 0.081 \\
\hline & $\begin{array}{l}\text { Ecological } \\
\text { construction }\end{array}$ & 0.619 & 0.201 & 0.078 & 0.102 \\
\hline \multirow{4}{*}{ d } & Costs & 0.532 & 0.317 & 0.099 & 0.052 \\
\hline & Benefits & 0.531 & 0.323 & 0.097 & 0.049 \\
\hline & $\begin{array}{l}\text { Development } \\
\text { potential }\end{array}$ & 0.531 & 0.334 & 0.111 & 0.024 \\
\hline & $\begin{array}{l}\text { Ecological } \\
\text { construction }\end{array}$ & 0.511 & 0.349 & 0.097 & 0.043 \\
\hline
\end{tabular}

$$
\begin{aligned}
& B_{4 a}=(0.506,0.259,0.165,0.070) \\
& B_{4 b}=(0.710,0.196,0.074,0.020) \\
& B_{4 c}=(0.619,0.201,0.078,0.102) \\
& B_{4 d}=(0.511,0.349,0.097,0.043)
\end{aligned}
$$

Consider the above evaluation vector as indicators of the upper evaluation matrix, the second floor of the evaluation results as shown in "Table IV".

TABLE IV. The SECOND EVALUATION RESUlts

According to the weight of the first level of evaluation factors, it is concluded that the level of comprehensive evaluation of four suppliers as follows:

$$
B_{a}=(0.5300,0.2455,0.1562,0.0683)
$$

$$
\begin{aligned}
& B_{b}=(0.7106,0.1901,0.0836,0.0157) \\
& B_{c}=(0.4578,0.2548,0.1325,0.1549) \\
& B_{d}=(0.5296,0.3233,0.0997,0.0474)
\end{aligned}
$$

Using the formula: $V=\sum_{j=1}^{m} V_{i} b_{i}(i=1,2,3,4)$, the conclusions are as follows:

$$
V_{a}=3.2372, V_{b}=3.5956, V_{c}=3.0155, V_{d}=3.3351
$$

Comparing the above value, $\mathrm{B}$ is the optimal supplier.

\section{CONCLUSION}

The third party logistics providers to become more and more enterprises realize the inevitable choice for customer demand rapid response. The paper establish evaluation index system of the third party logistics service supplier selection according to the characteristics of fresh agricultural products, and use fuzzy comprehensive evaluation method to select suppliers. Finally, the article selected case for empirical analysis, which provides effective decision basis for the enterprises to carry out the third party logistics supplier evaluation and selection.

\section{REFERENCES}

[1] Juntao He,Fei Wang.1987. China's Fresh Fresh agricultural products Supply Chain Problems And Optimization. Logistics engineering and management ,2010(3):64-66.

[2] Qiang Wang,Xiaodong Liu. Implement Precooling of Fresh agricultural products in Producing Area and Perfect Low Temperature Cold-chain. Refrigeration, 2001(1):40-44.

[3] Ning Li. 1982.Application of Fuzzy Comprehensive Evaluation in Logistics Business Outsourcing. Logistics Technology, 2011(30): 157159 . 